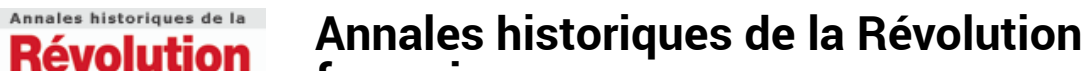

française française

364 | avril-juin 2011

Varia

\section{Histoire et engagement : avec Claude Mazauric}

\section{Marc Deleplace}

\section{OpenEdition}

Journals

Édition électronique

URL : https://journals.openedition.org/ahrf/12076

DOI : $10.4000 /$ ahrf.12076

ISSN : $1952-403 X$

Éditeur :

Armand Colin, Société des études robespierristes

Édition imprimée

Date de publication : 1 juin 2011

Pagination : 266-268

ISSN : 0003-4436

Référence électronique

Marc Deleplace, «Histoire et engagement : avec Claude Mazauric », Annales historiques de la Révolution française [En ligne], 364 | avril-juin 2011, mis en ligne le 31 août 2011, consulté le 22 avril 2022. URL http://journals.openedition.org/ahrf/12076 ; DOI : https://doi.org/10.4000/ahrf.12076

Ce document a été généré automatiquement le 22 avril 2022.

Tous droits réservés 


\title{
Histoire et engagement : avec Claude Mazauric
}

\author{
Marc Deleplace
}

\section{RÉFÉRENCE}

Histoire et engagement : avec Claude Mazauric, $\mathrm{n}^{\circ}$ spécial des Cahiers d'histoire. Revue d'histoire critique, $\mathrm{n}^{\circ}$ 104, avril-juin 2008, 224 p., ISBN 978-2-917541-08-1, $14 €$

1 Les Cahiers d'histoire présentent sous le titre "Histoire et engagement ", dans leur livraison d'avril-juin 2008, une série d'entretiens entre Claude Mazauric et Julien Louvrier. Rassemblés par ce dernier en vue d'une thèse sur « l'historiographie jacobine de la Révolution française dans la seconde moitié du $\mathrm{xx}^{\mathrm{e}}$ siècle ", ces entretiens offrent plusieurs possibilités de lecture, et ce n'est pas leur moindre intérêt. Menés avec vivacité par Claude Mazauric, ils comportent une part d'autobiographie qui n'est pas sans évoquer, quoique dans un registre différent, les essais d'ego-histoire publiés naguère sous la houlette de Pierre Nora. Interrogeant les liens entre le travail de l'historien et son engagement, ou plutôt ses engagements, ils pourraient figurer dans le Dictionnaire des intellectuels français de Michel Winock et Jacques Julliard. En fait, le propos de Julien Louvrier est avant tout historiographique. Il relève d'une démarche prosopographique dont les entretiens ici retranscrits donnent à espérer une analyse enrichissante d'un moment particulier de l'historiographie de la Révolution française.

2 On se laisse tout d'abord, avec un plaisir non dissimulé, entraîner par Claude Mazauric sur les chemins d'une existence en phase avec le siècle. Le rappel de ses origines est en même temps, puisque tel il le veut, une leçon d'histoire sociale (p. 21-40). L'individu certes, mais toujours pris dans le réseau dense des relations sociales dans lesquelles il s'inscrit et qui lui donnent en définitive sa consistance propre, depuis les années de jeunesse, l'expérience de la maladie, la formation intellectuelle, jusqu'à l'entrée dans le métier (p.55). Chemin faisant, Claude Mazauric affirme de fait une position méthodologique fondée dans une pratique universitaire de l'histoire née au tournant 
$\mathrm{du}$ XIX ${ }^{\mathrm{e}}$ siècle. Il se dit ainsi «historien des sources» et revendique tout au long des entretiens sa longue et «besogneuse » pratique des archives, en même temps qu'il fonde l'exposé de son ancrage familial dans l'horizon d'une histoire sociale appuyée sur une forte érudition (p. 25). L'évocation de la haute figure de Georges Lefebvre vient renforcer la revendication d'une forme d'héritage intellectuel et méthodologique assumé qui participe de la séparation d'avec François Furet, trop peu sur le «terrain » au goût de Claude Mazauric qui cite à ce propos Richard Cobb. Quelques figures, parmi bien d'autres, qui accompagnent ce long parcours, aussi bien dans son versant professionnel que militant, et amical. Figures trop souvent simplement évoquées peutêtre (à l'exception d'Albert Soboul, et secondairement de Michel Vovelle), notamment lorsqu'il s'agit d'aborder la question du travail accompli au sein de l'IHRF et de la SER, où la remémoration cède exceptionnellement le pas à l'analyse historique. Car disonsle, l'une des difficultés sans doute, à laquelle peut se heurter l'analyse de ces entretiens dans la perspective voulue par Julien Louvrier, peut bien provenir de ce que, à de rares exceptions près, Claude Mazauric ne cède pas sa position d'historien, voire de maître. Claude Mazauric s'affirme lui-même d'abord enseignant, au plein sens du terme et dans toutes les dimensions que cela implique. Son témoignage est ainsi constamment surplombé, et ce n'est guère étonnant, par le regard de l'historien. Tel est déjà le cas de l'exploration généalogique à laquelle il se livre au début de l'entretien (p. 21). Tel il demeure dans la suite, alternant, vis-à-vis de son interlocuteur, décentration et conseils.

3 Vient, très rapidement après le rappel de ses jeunes années, la question de l'engagement, puisque celui-ci s'est affirmé très tôt, et rapidement affermi, au feu de combats dont il est utile de rappeler qu'ils ne furent pas toujours sans risques, sur fond de lutte contre la guerre d'Indochine et la guerre d'Algérie (p. 58). C'est ici qu'il faut sans doute garder en mémoire que la publication de ces entretiens par les Cahiers d'histoire, aujourd'hui "revue d'histoire critique», naguère "revue d'histoire marxiste", relève également de l'hommage rendu à l'un de ceux qui en fut un participant assidu. Claude Mazauric ne se fait en effet pas faute de rappeler l'activité intellectuelle qui fut celle du CERM puis de l'IRM, devenu aujourd'hui Espace Marx, éditeur des Cahiers.

De cet engagement, Claude Mazauric nous offre une vision contrastée. D'une part, ce n'est en définitive qu'avec une certaine réticence qu'il s'exprime sur sa présence dans les instances dirigeantes d'un Parti qu'il n'a jamais renié, malgré des vicissitudes qu'il ne tait pas, récusant l'expression de «cadre du PCF » (p.79) et n'abordant qu'avec circonspection ses relations avec les cadres dirigeants dudit Parti (second entretien); de l'autre, il revient constamment sur l'entrelacement complexe de son engagement précoce et de son activité d'historien, au travers tout d'abord des sujets qui ont structuré cette activité (du projet de thèse initial sur Rouen à Babeuf et à la réflexion sur les origines du communisme) et de la pratique de l'histoire qui fut et demeure la sienne, ensuite par la place de la réflexion marxiste dans cette pratique, se disant avec quelque fierté « historien roturier», plutôt que "jacobin». Cette position, peut-être moins aisée à discriminer qu'il ne veut bien le dire, se définissant lui-même comme historien et intellectuel engagé, et non comme historien engagé, s'enracine à la fois dans une histoire familiale et personnelle (seul moment où Claude Mazauric semble céder à une forme de déterminisme historique qu'il récuse avec insistance par ailleurs) et dans sa formation et sa démarche intellectuelle. 
5 L'un des temps fort de ce témoigne est bien ainsi celui où Claude Mazauric aborde la question de son rapport au marxisme (p. 95-102). S'il se revendique « disciple de Marx » (p. 95) et s'affirme « adepte convaincu du matérialisme historique » (p. 96), il marque en revanche d'emblée la distance avec toute appréhension pouvant relever d'une philosophie de l'histoire. Aussi propose-t-il une analyse critique du schéma de la succession des modes de production, ainsi que de la distinction entre base matérielle et superstructure (p.97-98). De même n'accepte-t-il en dernière instance le recours à la «lutte des classes», qualifiée «d'extraordinaire instrument d'approche de la dialectique historique ", qu'à la condition « de n'en pas faire un usage métaphorique ou une explication passe-partout» (p.101). Ces propos invitent donc à une réévaluation critique de la présence de la pensée de Marx dans l'historiographie française, hors de tout jugement dogmatique (pour une introduction à cette question, voir Thierry Aprile, "Marxisme et Histoire ", Historiographies, I, Concepts et débats, C. Delacroix, F. Dosse, P. Garcia et N. Offenstadt, dir., Gallimard, Folio-histoire, 2010), et pas seulement celle de la Révolution, pour laquelle on trouvera sous la plume même de Claude Mazauric de plus amples développements (L'Histoire de la Révolution française et la pensée marxiste, Paris, PUF, 2009). D'une certaine manière, Claude Mazauric paraît ne pas renoncer à un «positivisme» historique (p.73-74, terme dont nous usons ici sans aucune valeur péjorative, mais en référence aux fondements de l'école historique française), fortement ancré dans l'historiographie française, et que traduit le rappel de l'irréductible singularité de l'événement historique qui conduit à révoquer en doute le déterminisme historique (« opacité » des configurations historiques, p. 101).

Il présente ainsi la figure d'une génération qui a pu effectivement concilier discipline de parti, acceptation du "centralisme démocratique» et réelle indépendance intellectuelle (notamment dans son rapport au marxisme). Une conciliation qui n'allait pas nécessairement de soi, si l'on en juge par la virulence des conflits, et des ostracismes, qui en ont parfois été le prix, soit dans l'institution universitaire, soit au sein du Parti lui-même comme de ses organisations adjacentes, point sur lequel Claude Mazauric ne s'étend guère, assurant n'en avoir pas eu à souffrir véritablement. Pas plus qu'il ne revient volontiers sur la longue polémique avec François Furet, préférant renvoyer à la biographie d'Albert Soboul récemment publiée par lui-même (Nérac, éditions d'Albret, 2004). Ajoutons que cet engagement, hautement revendiqué, dans la pleine liberté intellectuelle, se nourrit également d'un double attachement à la République, celle de l'école, qui lui permit après son père d'évoluer hors de sa condition familiale, et celle de la santé publique, qui lui sauva la vie. Attachement à nouveau fondé dans l'expérience personnelle, et renforcé par le rôle joué par les communistes dans la République de l'après-guerre.

7 Revenons pour conclure sur le projet de l'auteur de l'entretien, qui nous semble, dans le principe, pouvoir s'inscrire dans la lignée des travaux d'O. Dumoulin ou de F. Dosse. On ne peut que souhaiter son aboutissement tant il nous semble vrai que la réflexion sur les modalités de l'élaboration de la connaissance historique est l'une des conditions de cette connaissance même. La présence, depuis maintenant près de 20 ans et au travers de nombreux aléas, d'une épreuve consacrée à cette dimension de la réflexion historique parmi les épreuves du concours de recrutement des enseignants d'histoire et géographie du second degré, épreuve qui n'oublie ni que l'histoire ne peut se séparer de l'historien (H.-I. Marrou, De La Connaissance historique, 1954), ni «Comment l'histoire fait-elle l'historien" (A. Prost, Vingtième siècle. Revue d'histoire, 65, janvier-mars 2000, 
p. 3-12), en est l'un des signes. Riche expérience humaine que celle de l'histoire, dont témoigne ici Claude Mazauric. 